\title{
Os Registros Semióticos em equações do primeiro grau: uma análise sobre livros didáticos do Ensino Fundamental
}

\section{Semiotic Registers of first grade equations: an analysis of Middle School textbooks}

\author{
Vanessa da Silva Pires \\ Universidade Federal do Rio Grande do Sul (UFRGS), Instituto de Matemática e Estatística, Pós- \\ Graduação em Ensino de Matemática, Porto Alegre, RS, Brasil \\ https://orcid.org/0000-0001-8336-6021, nessavsp25@gmail.com
}

\section{Jeremias Stein Rodriguês Instituto Federal de Santa Catarina (IFSC), Departamento Acadêmico de Linguagem, Tecnologia, Educação e Ciência (DALTEC), Florianópolis, SC, Brasil https://orcid.org/0000-0002-7869-5856, jeremias.stein@ifsc.edu.br}

\section{Informações do Artigo \\ Como citar este artigo \\ PIRES, Vanessa da Silva; RODRIGUÊS, Jeremias Stein. Os Registros Semióticos em Equações do Primeiro Grau: uma análise sobre livros didáticos do Ensino \\ Fundamental. REMAT: Revista Eletrônica da Matemática, Bento Gonçalves, RS, v. 6, n. 2, p. e2005, 16 set. 2020. DOI: \\ https://doi.org/10.35819/remat2020v6i2id3919}

\section{Histórico do Artigo}

Submissão: 26 de fevereiro de 2020.

Aceite: 3 de junho de 2020 .

Palavras-chave

Ensino e Aprendizagem de Matemática

Equação do Primeiro Grau

Registros de Representação Semiótica

\section{Keywords}

Mathematics Teaching and Learning

First Grade Equation

Registers of Semiotic Representation

\section{Resumo}

A abordagem do conceito de equações do primeiro grau com uma incógnita em livros didáticos, do Ensino Fundamental, viabiliza o acesso e a aprendizagem do objeto matemático com base nas perspectivas da Teoria de Registros de Representação Semiótica (TRRS)? Para isso, tomamos como objetivo analisar livros didáticos de forma a verificar se o uso das representações empregadas no conteúdo de equações do primeiro grau, no sétimo ano do Ensino Fundamental, vai ao encontro dos princípios de aprendizagem da TRRS. Deste modo, foi realizada uma pesquisa bibliográfica em três livros didáticos de Matemática do sétimo do Ensino Fundamental, listados pelo PNLD 2017. A análise do material foi feita em conjunto com a TRRS, de Raymond Duval, na qual se afirma que na aprendizagem da Matemática a compreensão do saber tem relação direta com a coordenação das representações do objeto matemático. Analisamos então as representações semióticas das equações do primeiro grau em cada livro e como estas, assim como os procedimentos cognitivos da teoria, foram utilizadas. Os resultados obtidos apontam que a utilização dos registros de representação semiótica poderia ser abordada de uma forma mais completa, de modo que o livro melhor auxilie no processo de ensino e aprendizagem.

\section{Abstract}

Does the approach to the concept of first grade equations in one variable presented in Middle School textbooks allow the access and the learning of the mathematical object based on the perspectives of the Theory of Registers of Semiotic Representation (TRSR)? To answer this question, textbooks were analyzed to verify if its use of representations on first grade equations content, in the seventh grade of Middle School, points to the same direction of the TRSR principles. Thereby, we made bibliographic research in three Mathematics seventh grade textbooks, listed in the PNLD 2017. The analysis of the textbooks was made in conjunction with the TRSR, of Raymond Duval, which indicates that in the learning of Mathematics the comprehension of concepts has a direct relation with the coordination of a mathematical object's representations. Then we analyzed the semiotic representations of the first grade equations presented in each textbook and how those, as well as the cognitives processes of the theory, were used. The results show that the use of a semiotic register of representations could be better addressed, making that the textbook could be much more useful to the teaching and learning process. 


\section{Introdução}

A compreensão de como se dá o processo de ensino e aprendizagem da Matemática é algo que está em constante desenvolvimento. Nesse sentido, para este texto, tomamos como base as perspectivas apresentadas pela Teoria de Registros de Representação Semiótica (TRRS), de Raymond Duval. Aqui, a palavra semiótica denota a ideia de signo, melhor dizendo, a ciência que estuda os signos. Santaella (2002, p. 13) diz que a semiótica é a "ciência que tem por objeto de investigação todas as linguagens possíveis, ou seja, que tem por objetivo o exame dos modos de constituição de todo e qualquer fenômeno como fenômeno de produção de significado e sentido". Portanto, a semiótica busca compreender e revelar as formas como cada pessoa dá significado às coisas ao seu redor. Duval (2003; 2009) nos indica que a TRRS tem como finalidade compreender como as distintas representações, de um mesmo objeto matemático, influenciam em processos cognitivos relacionados ao ensino e aprendizagem de Matemática.

Como o livro didático é um recurso muito utilizado em nosso sistema de ensino, por grande parte dos professores e de maneira parcial ou integral em sala de aula, este material tem grande relevância no processo de ensino e aprendizagem, de modo que a sua elaboração deva ser feita considerando as diversas nuances do ensino. De acordo com Guimarães et al. (2008, p. 3):

O livro didático se constitui em um importante recurso utilizado por professores na condução e/ou elaboração das abordagens de ensino, em parte pela ausência de outros materiais que orientem os professores sobre o quê e como ensinar, e em parte pela frequente dificuldade de acesso do estudante a outras fontes de estudo e pesquisa.

No Brasil, a distribuição deste material na rede pública de ensino básico é feita pelo Programa Nacional do Livro Didático (PNLD), sendo que, em alguns casos, uma listagem dos livros disponíveis é apresentada, sendo responsabilidade da escola a escolha do livro a ser utilizado pelos seus estudantes. Os exemplares distribuídos são avaliados pelo Ministério da Educação, seguindo uma série de critérios estabelecidos de acordo com os Parâmetros Curriculares Nacionais de cada disciplina. Atualmente esse material é distribuído para todos os anos da rede pública de ensino brasileiro, inclusive a Educação de Jovens e Adultos, de modo que se constituem como elementos fundamentais do ensino escolar brasileiro. Assim, a análise de como os conteúdos estão sendo apresentados nos livros didáticos é de grande relevância, seja para uma escolha mais crítica do livro ou para que o professor consiga observar suas limitações.

Há muito o ensino de equações do primeiro grau (EPG) com uma incógnita se faz presente nos livros didáticos. Atualmente este conteúdo se faz presente em livro do sétimo ano do Ensino Fundamental, período de grande importância para o ensino de Matemática, visto que é o momento em que o estudante começa a ser introduzido a conceitos e procedimentos algébricos. Historicamente, segundo Rodriguês e Costa (2019), a introdução do ensino de equações no ensino elementar se caracteriza como de grande relevância, pois no início do século XX tais conteúdos ainda pertenciam ao ensino secundário, uma vez que eram vistos como de grande complexidade. Contudo, a constituição desse conteúdo para o currículo do ensino elementar tem 
como objetivo facilitar a aprendizagem e resolução de problemas atrelados a outros conteúdos da Matemática (RODRIGUÊS; COSTA, 2019).

Muitas mudanças ocorrem para a aprendizagem do estudante, pois é nesse momento que ele tem seu primeiro contato com incógnitas, um valor desconhecido, bem como a busca por processos e procedimentos de generalização da Álgebra. Isto faz com que este seja um momento importantíssimo no processo de ensino e aprendizagem da Matemática, e que há dificuldade na compreensão de alguns conceitos por parte dos estudantes.

A partir destas considerações buscamos fazer uma análise da abordagem deste conteúdo em três livros didáticos do Ensino Fundamental, com base em uma análise documental em conjunto com a TRRS. Assim, buscamos investigar se a forma como são abordados tais conceitos nos livros didáticos possibilita ao estudante os processos de transição entre as diversas representações durante a construção do conceito, de modo a buscar uma resposta para a questão: A abordagem do conceito de equações do primeiro grau com uma incógnita em livros didáticos, do Ensino Fundamental, viabiliza o acesso e a aprendizagem do objeto matemático com base nas perspectivas da TRRS? Para buscar a resposta a este problema, a análise dos livros didáticos tem como foco as formas de representação abordadas no desenvolvimento do conteúdo de EPG e as diversas transformações viabilizadas neste processo.

Desta forma, vamos realizar uma pesquisa bibliográfica em três livros didáticos de Matemática do Ensino Fundamental, do sétimo ano, utilizados na região de Araranguá - SC e que foram escolhidos pelos professores a partir da listagem do PNLD 2017¹. Na análise, teremos como foco as formas de representações das EPG bem como as diferentes transformações, inter e intra registro, abordadas em cada um deles.

\section{Fundamentação teórica}

Para Oliveira (2002, p. 35) "A Álgebra, consiste em um conjunto de afirmações, para os quais é possível produzir significados em termos de números e operações aritméticas, possivelmente envolvendo igualdade ou desigualdade". De caráter abstrato e considerada pelos estudantes de difícil compreensão, Usiskin (1995, p. 21) afirma que a Álgebra "[...] é a chave para a caracterização e a compreensão das estruturas matemáticas". Nesse sentido, Ponte (2003) avalia que a equação é o conceito central da Álgebra, por ser uma nova forma de expressar a Matemática, com o uso de letras/símbolos e uma diferente maneira de manipulação, levando a um outro nível de abstração. Sobre equação, Menezes (1970, p. 121) afirma que:

[...] Equação é a igualdade cujos dois membros somente se tornam iguais para certos valores, chamados raízes da equação, atribuídos a determinadas letras neles contidas, denominadas incógnitas. A equação é, portanto, uma igualdade condicionada.

Esse condicionamento da igualdade de uma equação pode ser um fator elementar para a dificuldade que se observa em sala de aula. Silva (2007, apud CAMARGO, 2014) vai além, o autor

${ }^{1}$ Disponível em: http://www.fnde.gov.br/pnld-2017/. 
aponta que a mudança da Matemática de contas para a Matemática algébrica, da abstração, gera muitas dificuldades nos estudantes, uma vez que essas "duas Matemáticas" são ensinadas separadamente, sendo a segunda abordada formalmente apenas nos anos finais do Ensino Fundamental.

Foram as dificuldades em aprendizagem de Matemática que levaram Raymond Duval a desenvolver estudos significativos sobre Psicologia Cognitiva de forma a aliar o uso das diversas representações na Matemática ao processo de ensino e aprendizagem da mesma. O pesquisador é autor da TRRS, apresentada em sua maior obra, Sémiosis et pensée humanie, em que discute esta teoria que cada vez mais se faz presente em estudos da aprendizagem de Matemática.

Uma vez que os objetos matemáticos pertencem ao campo das ideias, a atividade Matemática é caracterizada pela dependência das representações semióticas e a grande variedade destas representações. De fato, as representações semióticas assumem um papel considerável, já que os objetos matemáticos se tornam acessíveis apenas através de suas representações, sendo que, além disso, um mesmo objeto matemático poderá ter diversas representações, em que cada uma evidenciará diferentes conteúdos do objeto estudado. Nesse sentido, Moretti (2002, p. 347) afirma que a linguagem discursiva não oferece as mesmas possibilidades que a forma figural ou em diagrama, sendo assim, segundo o autor, "de um ponto de vista cognitivo uma representação é parcial em relação aquilo que ela quer representar e que de um registro a outro não são os mesmos conteúdos de uma situação que são representados". Ele exemplifica: consideremos as diferentes representações cartesianas da mesma parábola

a) $y=x^{2}-4 x+3$

b) $y+1=(x-2)^{2}$

c) $y=(x-3)(x-1)$

d) Esboço da parábola no plano cartesiano

Segundo Moretti, cada um dos itens anteriores faz referência a um mesmo objeto matemático, no entanto:

[...] do ponto de vista cognitivo, um certo tipo de informação sobressai mais em uma do que em outra forma: em (c) vemos com clareza as raízes; em (b), as coordenadas do vértice da parábola; em (d), uma representação em um sistema semiótico diferente dos anteriores e que em muitas vezes é bastante adequada à interpretação, se for o caso, do fenômeno representado (MORETTI, 2002, p. 347).

Para Duval (2003), se o estudante tem acesso a apenas um registro de representação, isso pode significar uma limitação na sua capacidade de reconhecimento dessas diferentes representações. Ele afirma que “Existe um 'enclausuramento' de registro que impede o estudante de reconhecer o mesmo objeto matemático em duas de suas representações bem diferentes" (Duval, 2003, p. 21). Portanto, não podemos negar a importância da pluralidade de registros de representação. Duval (2003, p. 31) ainda aponta que

Há uma pluralidade de registros de representação de um mesmo objeto, e a articulação desses diferentes registros é condição para a compreensão em 
matemática, embora várias abordagens didáticas não levem em conta esse fato. É enganosa a ideia de que todos os registros de representações de um objeto tenham igual conteúdo ou que se deixem perceber uns nos outros.

Além da importância de reconhecer essa diversidade de registros, Duval afirma que outro fato importante quanto a utilização dos registros de representação semiótica é que "não se deve jamais confundir um objeto e sua representação" (DUVAL, 2003, p. 21), é então necessário que se estabeleça a distinção entre eles. É primordial a compreensão de que o registro de representação apenas evidencia e possibilita o acesso ao objeto matemático, bem como alguns de seus conteúdos. Sendo assim $2 ; 1+1 ; 4-2 ; 6 \div 3$; dois; entre outras; são representações diferentes referentes ao mesmo objeto matemático.

As representações semióticas são, portanto, essenciais para a atividade cognitiva do pensamento e, segundo Duval (2003), duas atividades devem ser possíveis entre as representações de um objeto matemático: tratamento e a conversão. Segundo o autor, os tratamentos podem ser entendidos como "transformações dentro de um mesmo registro" (DUVAL, 2003, p. 16). Por exemplo, o desenvolvimento do cálculo de uma expressão numérica respeitando a ordem de resolução das operações envolvidas até se obter o resultado final, é considerado uma sucessão de tratamentos, desde que se mantenha o uso de uma mesma escrita simbólica dos algarismos. Já a conversão consiste no processo de transformação de um registro em outro, quando ocorre mudança de sistema de registro conservando a referência ao objeto, sendo assim o registro de partida é diferente do registro de chegada. Por exemplo, a expressão "equação polinomial do segundo grau" pode ser convertida para " $a x^{2}+b x+c=0$ ", sendo esta uma conversão partindo de uma representação em língua natural para um registro algébrico.

Figura 1 - Distinção entre tratamento e conversão.

\begin{tabular}{|c|c|}
\hline \multicolumn{2}{|c|}{$\begin{array}{l}\text { Transformação de uma representação semiótica } \\
\text { em uma outra representação semiótica }\end{array}$} \\
\hline $\begin{array}{l}\text { Permanecendo no mesmo sistema: } \\
\text { TRATAMENTO }\end{array}$ & $\begin{array}{l}\text { Mudando de Sistema, mas conservando a } \\
\text { referencia aos mesmos objetos: CONVERSÃO }\end{array}$ \\
\hline $\begin{array}{l}\text { Quase sempre, é somente este tipo de } \\
\text { transformação que chama a atenção porque ele } \\
\text { corresponde a procedimentos de justificação. } \\
\text { De um ponto de vista "pedagógico", tenta-se } \\
\text { algumas vezes procurar o melhor registros de } \\
\text { representação a ser utilizado para que os alunos } \\
\text { possam compreender. }\end{array}$ & $\begin{array}{l}\text { Este tipo de transformação enfrenta os fenômenos } \\
\text { de não-congruência. Isso se traduz pelo fato de os } \\
\text { alunos não reconhecerem o mesmo objeto através } \\
\text { de duas representações diferentes. } \\
\text { A capacidade de converter implica a coordenação } \\
\text { de registros mobilizados. Os fatores de não- } \\
\text { congruência mudam conforme os tipos de registros } \\
\text { entre os quais a conversão é, ou deve ser, } \\
\text { efetuada. }\end{array}$ \\
\hline
\end{tabular}

Fonte: DUVAL (2003, p. 15). 
A seguinte atividade nos auxilia a compreender melhor a diferença de tratamentos e conversões: "Escreva uma equação que represente o cálculo do perímetro de um quadrado de lado L. Em seguida determine o perímetro se o quadrado possuir lado 1, 2 e 3. Faça então a representação gráfica que esboça esta situação". Aqui podemos destacar o uso de tratamentos quando a figura em duas dimensões é manipulada para se observar que o período é quatro vezes o lado ou quando efetuamos o cálculo do perímetro para os lados iguais a 1, 2 e 3. Do mesmo modo, diversas conversões são necessárias, como a mudança da língua natural para o registro figural, da língua natural/registro figural para o registro algébrico, do registro algébrico para o registro gráfico. Na Figura 2, apresentamos o esquema desta situação-problema.

Figura 2 - Tratamentos e conversões possibilitados pela situação-problema.

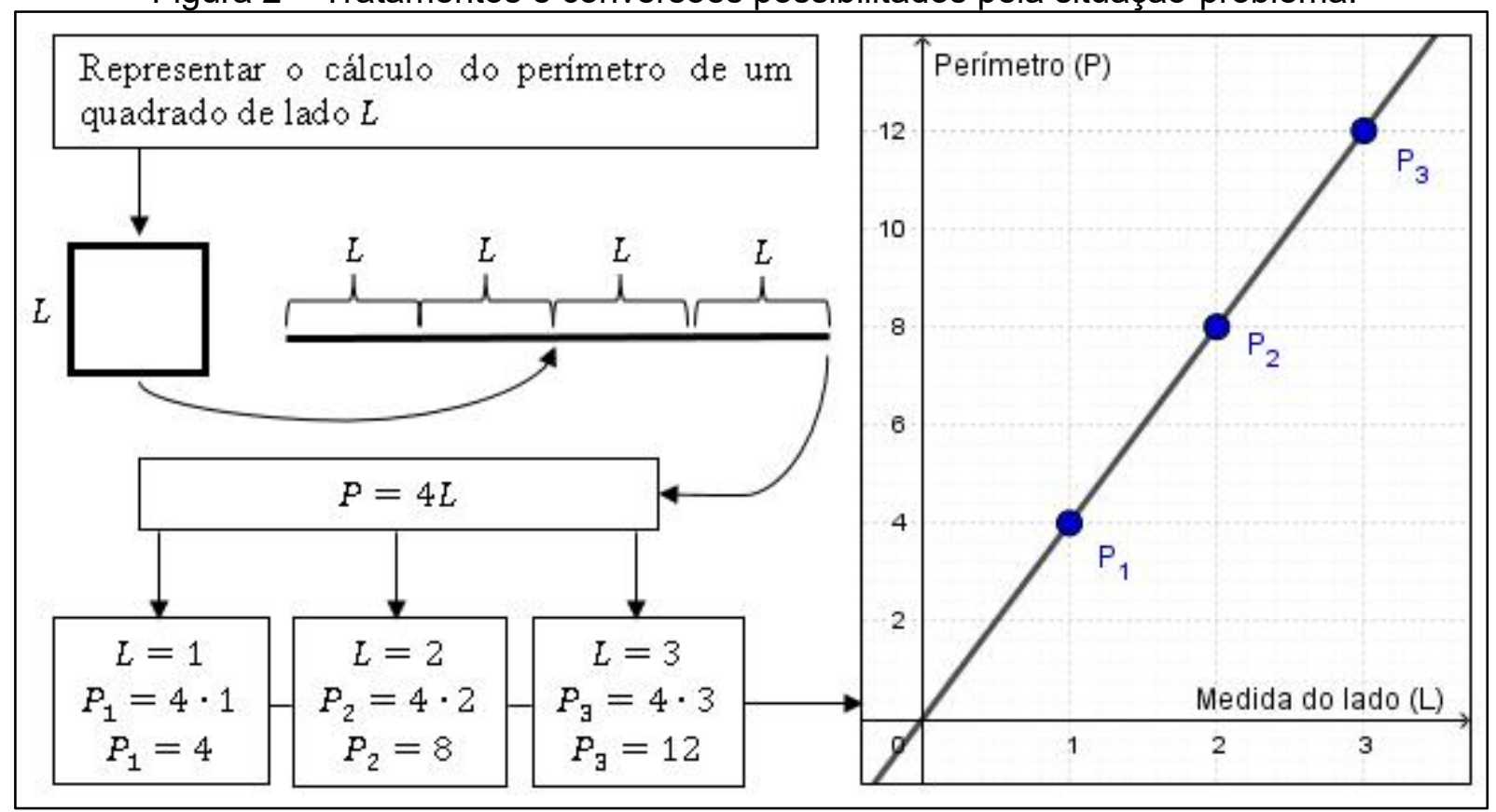

Fonte: Elaborado pelos autores (2020).

Desse modo, comumente fazemos uso do que Duval chama de tratamento e conversão, mesmo sem saber. Contudo, a relevância dessas atividades está no fato que, segundo a TRRS, é a atividade de conversão a responsável pela construção do conhecimento acerca do objeto estudado, ou seja, pela apropriação do saber. Segundo Duval, "a compreensão matemática está intimamente ligada ao fato de dispor de ao menos dois registros de representação diferentes" (2003, p. 22). Assim, é através da coordenação de ao menos dois registros semióticos que o processo de aprendizagem matemática será bem-sucedido.

Desta forma, Duval (2003, p. 30) destaca que “[...] se se quer analisar as dificuldades de aprendizagem em matemática, é preciso estudar prioritariamente a conversão das representações e não os tratamentos". Partindo destes pressupostos utilizaremos as ideias de Duval, nos baseando nas hipóteses formuladas por ele e nos livros didáticos selecionados para desenvolvermos nossa análise, sendo o ensino de EPG o nosso objeto de estudo. A escolha por tal tema se dá pelo fato de que este conceito é muito importante na formação dos estudantes e 
possui diversas aplicabilidades em situações cotidianas, assim como se constitui como parte fundamental da compreensão da Álgebra na Matemática.

\section{Metodologia}

Neste artigo realizamos uma análise sobre livros didáticos listados no PNLD, o que faz com que essa investigação detenha os aspectos de uma pesquisa bibliográfica. De acordo com Gil (2007, p. 44), os exemplos mais característicos desse tipo de pesquisa se propõem à análise das diversas posições acerca de um problema, deste modo nos pareceu apropriado desenvolver a análise com três livros didáticos, de forma que diversas abordagens pudessem fazer parte desta discussão. Nesse sentido, Fonseca (2002, p. 32) indica que "A pesquisa bibliográfica é feita a partir do levantamento de referências teóricas já analisadas, e publicadas por meios escritos e eletrônicos, como livros, artigos científicos, páginas de web sites". No que Gil (2007, p. 44) complementa dizendo que "Embora em quase todos os estudos seja exigido algum tipo de trabalho dessa natureza, há pesquisas desenvolvidas exclusivamente a partir de fontes bibliográficas".

Aliado a isto utilizamos a TRRS para o desenvolvimento da pesquisa bibliográfica ou, mais precisamente, para a análise dos livros didáticos acerca do conteúdo de EPG. Aqui, a teoria de Duval nos ajuda a indicar a direção das análises, assim igualmente tomando a forma de referencial metodológico. Para analisar como os livros apresentam e abordam o conteúdo de EPG, de forma a garantir o acesso e aprendizagem do estudante a este conteúdo, a TRRS aponta que a investigação deve recair sobre os registros utilizados no livro didático. Contudo, como discutido anteriormente, a teoria ainda nos mostra que não basta apenas o uso dos diversos registros semióticos de um mesmo objeto matemático, mas sim se este material possibilita a coordenação de diferentes registros pelo estudante. Assim, nos debruçamos sobre os diversos usos e empregos dos registros semióticos nos livros didáticos, bem como das atividades cognitivas feitas ou solicitadas explicita ou implicitamente, principalmente as conversões, no desenvolvimento do conteúdo, dos exemplos e exercícios.

Desta forma, apresentamos uma análise de três livros didáticos de Matemática do sétimo ano do Ensino Fundamental, listados pela PNLD 2017, comparando as formas de representações abordadas em cada um deles no que se refere a parte do conteúdo, de exemplos resolvidos e exercícios sobre EPG com uma incógnita. Assim, não nos ativemos às seções anteriores ou posteriores ao capítulo direcionado às EPG com uma incógnita, buscando nesta porção do livro didático pelos elementos que apontassem favoravelmente, ou não, para as perspectivas de aprendizagem segundo a TRRS. Os livros selecionados foram os das coleções Projeto Araribá, de autoria coletiva, Projeto Teláris, de Luiz Roberto Dante, e Matemática Bianchini, de Edwaldo Bianchini. A seleção destes livros didáticos se deu pelo fato de estes serem os livros distribuídos para os professores para a utilização na região de Araranguá, onde a pesquisa foi realizada. 


\section{Resultados e discussões}

A introdução aos conhecimentos algébricos é um dos momentos em que muitos estudantes têm dificuldade, devido ao avanço cognitivo em relação aos procedimentos aritméticos, bem como pela sua linguagem simbólica que é nova aos estudantes. No entanto, segundo os PCNs (Brasil, 1998, p. 115), "o estudo da Álgebra constitui um espaço bastante significativo para que o estudante desenvolva e exercite sua capacidade de abstração e generalização, além de lhe possibilitar a aquisição de uma poderosa ferramenta para resolver problemas".

Para o estudo bibliográfico, com base na TRRS, foi possível efetuar a análise dos livros didáticos selecionados buscando observar como os autores das obras analisadas utilizam das diferentes formas de representação do objeto das EPG, na busca por um melhor ensino e aprendizagem do estudante. A análise teve como foco as diversas formas de apresentar o objeto matemático, ou seja, o desenvolvimento do conteúdo, a proposta de desenvolvimento dos exercícios.

O livro Projeto Araribá (Figura 3) e o livro Projeto Teláris (Figura 4), iniciam a seção apresentando a definição de EPG fazendo uso de uma representação que mescla a língua natural e o registro algébrico. O Projeto Araribá apresenta dois exemplos algébricos, podendo, talvez, ser considerado uma conversão de um registro misto para uma representação inteiramente algébrica, além de identificar os valores dos coeficientes a e b, um tratamento comum no registro algébrico. Cabe destacar ainda que o Projeto Teláris apresenta, além da definição, uma ilustração em que explica porque a EPG recebe este nome, contudo a ilustração não tem nenhum aspecto de ensino.

Figura 3 - Definição de EPG no Projeto Araribá.

Agora, você vai aplicar as equações equivalentes para resolver
equações do $1^{\circ}$ grau com uma incógnita.
As equações do $1^{\circ}$ grau com apenas uma incógnita podem ser
escritas como uma equação equivalente da forma $a x+b=0$, em
que $a$ e $b$ são números racionais conhecidos e $a$ é diferente de zero.
Nesse caso, a incógnita é $x$.
Exemplos
$\bullet 3 x+1=0\left\{\begin{array}{l}a=3 \\ b=1\end{array} \bullet-\frac{x}{2}=0\left\{\begin{array}{l}a=-\frac{1}{2} \\ b=0\end{array}\right.\right.$

Fonte: Editora Moderna (2014, p. 141).

Figura 4 - Definição de EPG apresentada no Projeto Teláris.

Uma equação é do $1^{\circ}$ grau com uma incógnita $(x)$ quando pode ser escrita na forma $a x=b, c o m a \neq 0$.

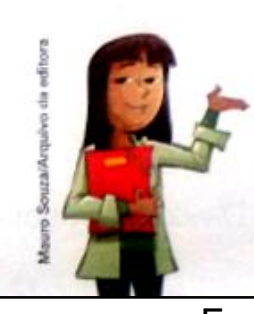

A equaçãoé

"do $1^{\circ}$ grau" porque o maior expoente que aparece na incógnita é 1 .

É "com uma incógnita" porque há somente um elemento desconhecido.

Fonte: Dante (2015, p. 127). 
Já o livro Matemática Bianchini (Figura 5), inicia o conteúdo com quatro exemplos de equações com o registro algébrico, dentre os quais os dois primeiros são representações de EPG com uma incógnita. Em seguida, o autor explica o motivo de os dois primeiros itens serem EPG em uma incógnita usando a língua natural.

Figura 5 - Definição de EPG apresentada no livro Matemática Bianchini.

Considere estas equações como exemplos.
a) $2 x+7=5$
c) $5 x^{2}-8 x+7=0$
b) $3 x+2=x-3$
d) $x+y=0$

As duas primeiras equações têm uma só incógnita (a letra $x$ ) com expoente 1 . Elas são exemplos de equações do 1ํgrau com uma incógnita; as outras não são. Fonte: Bianchini (2015, p. 110).

Sendo assim, devemos ressaltar que nenhum dos três livros, na parte de introdução e definição, aborda o conceito de EPG com uma incógnita usando um registro inteiramente na língua natural, como por exemplo "o triplo de um número adicionado a cinco resulta em oito". Tal abordagem permitiria a relação do novo conteúdo com ideias vistas nos anos anteriores e a relação com os conhecimentos aritméticos dos estudantes. Do mesmo modo, nenhum dos livros traz o uso do registro figural, geralmente denotado pela balança, o que poderia auxiliar a destacar a relevância da igualdade no desenvolvimento de qualquer equação algébrica, ou seja, de que o valor da incógnita faz com que os dois lados da igualdade tenham como resultado o mesmo número. Assim, importantes conversões não são incentivadas pelos livros na introdução do objeto estudado, cabendo ao professor a apresentação e uso, ou não, destas representações na introdução do conteúdo.

Em seguida focamos em como os autores apresentam a forma de resolução da EPG com uma incógnita. Neste ponto encontramos abordagens distintas.

Figura 6 - Resolução de EPG no Projeto Araribá.

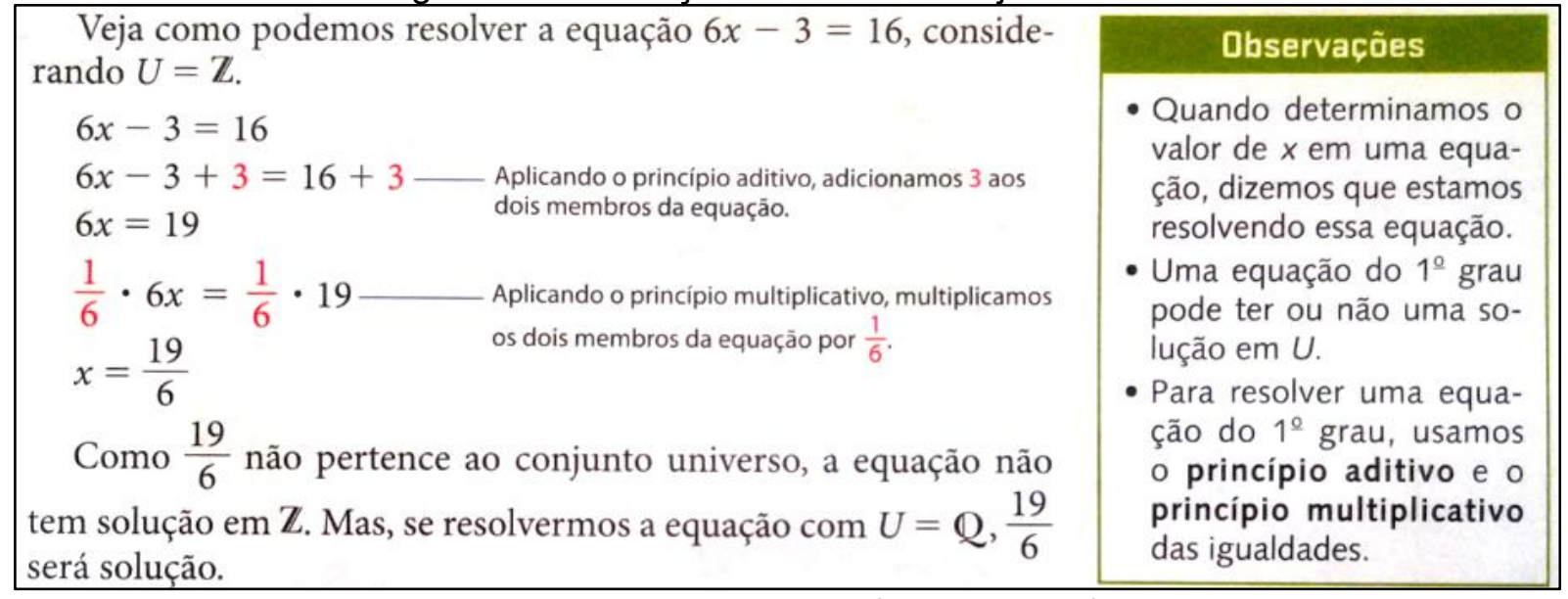

Fonte: Editora Moderna (2014, p. 141).

Na Figura 6, observamos que o autor apresenta uma equação na linguagem algébrica, em seguida realiza uma sequência de tratamentos, apresentados no registro algébrico e, ao lado, na 
língua natural, até encontrar o valor da incógnita, concluindo que dentro do conjunto universo dado não há solução para a equação. Sendo este o único exemplo de resolução trabalhado no livro nesta seção, o autor não faz uso de outro registro que não o algébrico, somente voltando as resoluções em um capítulo de aplicações. Esta abordagem, contudo, não chega a se caracterizar como uma conversão nas perspectivas da TRRS, uma vez que apenas os tratamentos, caracterizados pelo princípio aditivo e multiplicativo, são convertidos em outro registro.

Já Bianchini (2015) prefere exemplificar a resolução da equação partindo de um registro figural, a imagem da balança em equilíbrio e deixando alguns blocos com valores desconhecidos (Figura 7). Em cada passo, o autor realiza uma conversão do registro figural para o algébrico, seguida de um tratamento apontado em língua natural que é feito no registro figural de forma a buscar pela solução do problema. Devemos notar que os tratamentos feitos na língua natural não são apresentados nos registros figural ou algébrico, como o primeiro em que se retira um cubo de cada lado da balança e que na equação seria representado pela subtração da incógnita dos dois lados da igualdade. Com os registros apresentados de forma mais completa talvez fosse possível para os estudantes uma compreensão do conteúdo e da coordenação dos dois registros utilizados.

Figura 7 - Resolução de EPG no livro Matemática Bianchini.

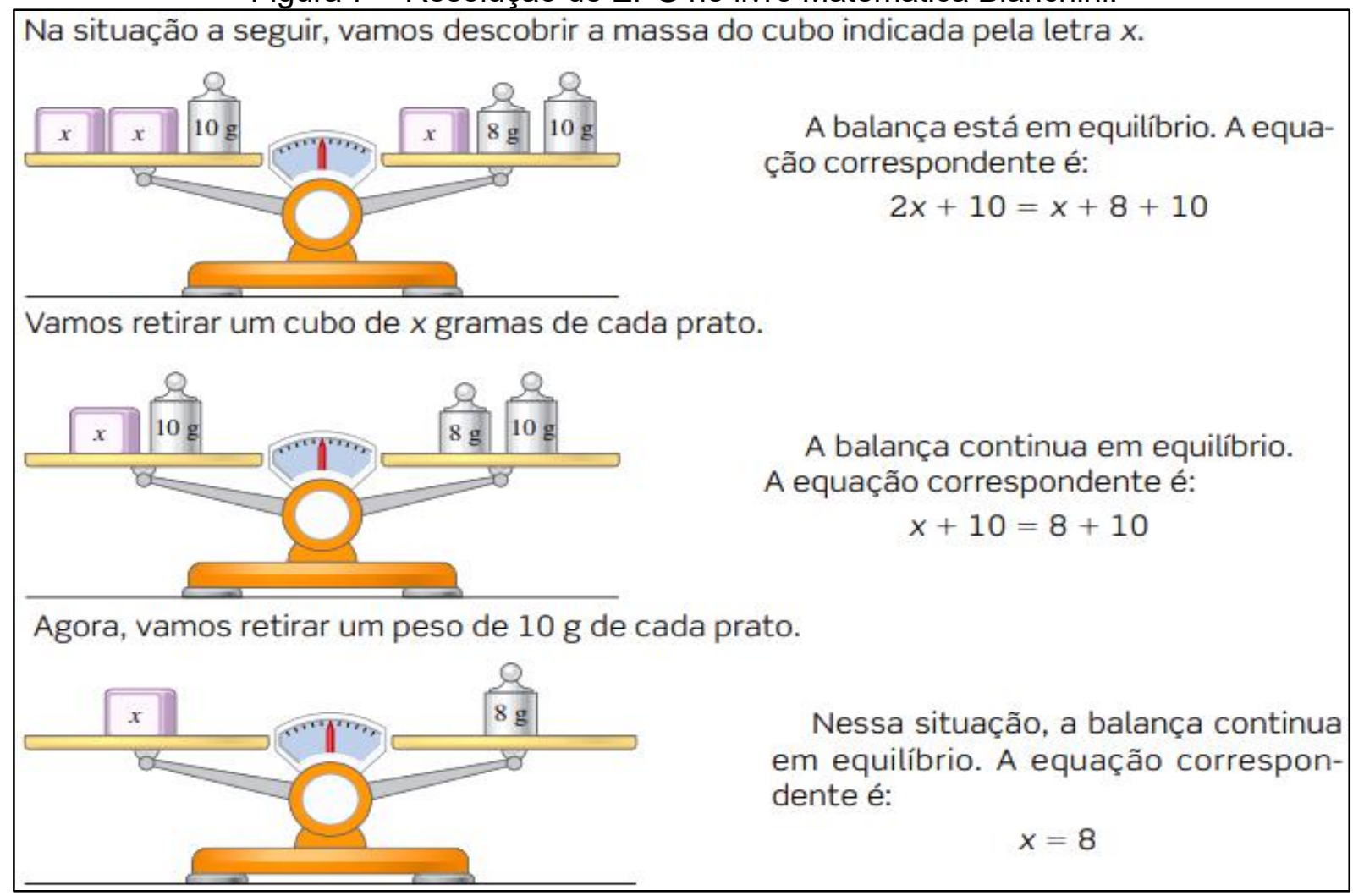

Fonte: Figura elaborada a partir de Bianchini (2015, p. 111-112).

No livro Projeto Teláris, Dante (2015) traz um exemplo inteiramente na linguagem natural (Figura 8), que não foi abordado em nenhum dos outros livros até esta parte da análise. $\mathrm{Na}$ sequência ocorre a conversão do registro em língua natural para o registro algébrico e, após alguns tratamentos neste último registro, é determinada e verificada a solução do problema. Dante 
ainda propõe mais dois exemplos semelhantes a esse utilizando o mesmo procedimento. Aqui, contudo, a conversão feita da língua natural para o registro algébrico é uma via de mão única, ou seja, não há um paralelo entre os registros ou ainda a volta ao registro inicial no decorrer da resolução. Assim, é difícil dizer que o uso feito dos dois registros levem a completa coordenação destes, principalmente quando observamos que um destes serve apenas de ponto de partida.

Figura 8 - Resolução de EPG no Projeto Teláris.

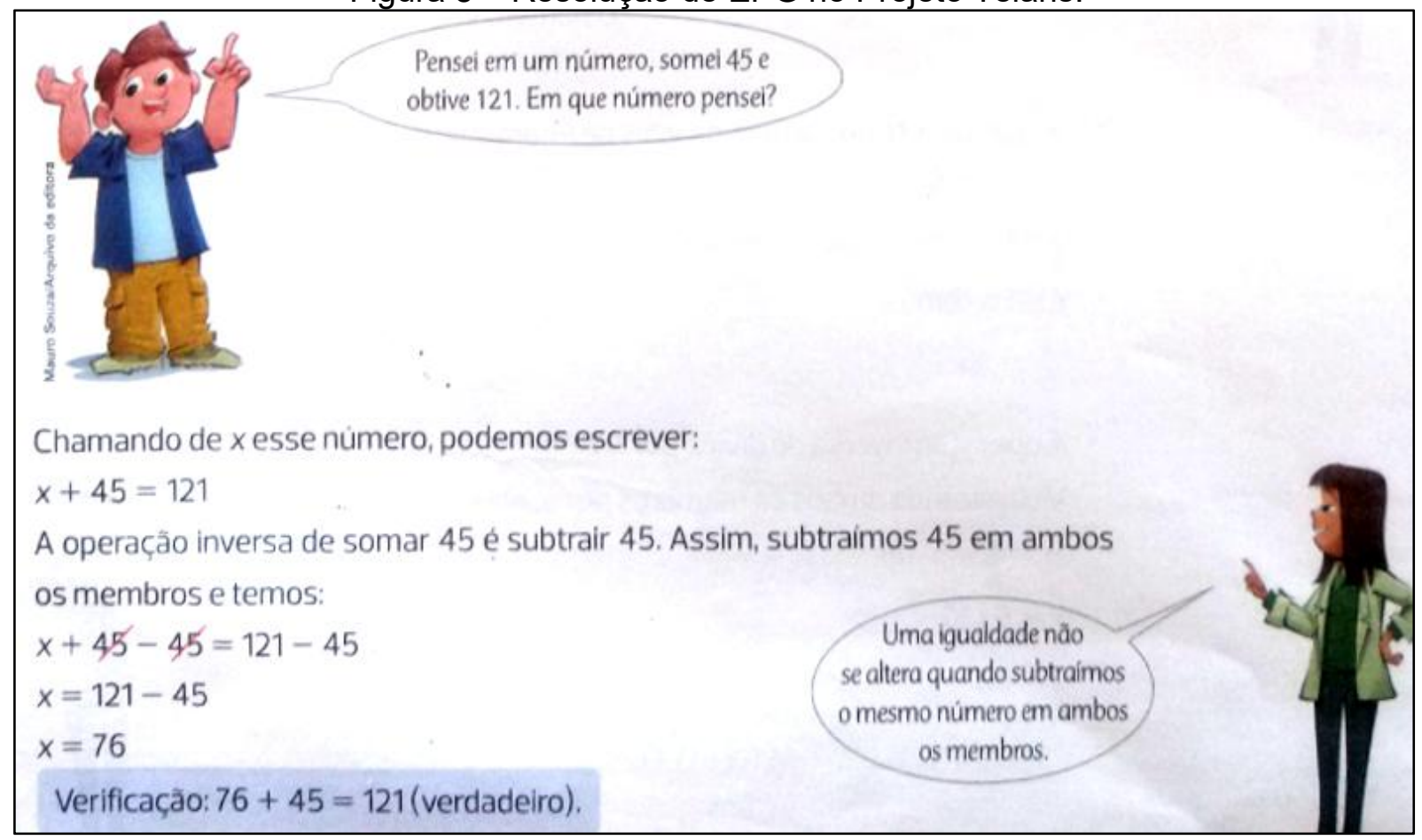

Fonte: Dante (2015, p. 127).

Ao finalizar esta parte, os três livros propõem atividades a serem desenvolvidas pelos estudantes. Na Figura 9, observamos os três exercícios a serem realizados no livro Projeto Araribá. A terceira questão é condizente com o exemplo resolvido no livro, em que se tem as equações na linguagem algébrica e se busca pela solução por meio de tratamentos. Nas questões 1 e 2 é proposta uma conversão do registro na língua natural para o figural/algébrico e, em seguida, a resolução de cada item. Tais abordagens não foram observadas no decorrer da parte analisada do livro, o que nos leva a pensar que atividades semelhantes devem surgir anteriormente no livro didático. Nas duas primeiras questões não há indícios de que se busque realizar a conversão dos registros figural e algébrico para o registro inicial, o que denota, mais uma vez, o sentido único do uso das conversões no livro didático.

Já o Projeto Teláris traz cinco atividades (Figura 10), sendo que na primeira se exige dos estudantes a resolução de problemas, propondo a conversão da linguagem natural para a algébrica, assim como proposto na resolução de exemplos. Observamos também, nas questões 25 e 27, que são apresentadas equações na linguagem algébrica em que se pretende descobrir a solução, sendo necessário a utilização de tratamentos como os utilizados nos exemplos do livro. $\mathrm{Na}$ última questão observamos novamente a solicitação para a conversão da língua natural para o 
registro algébrico, sendo que, desta vez, se procura também pela solução de cada item neste registro.

Figura 9 - Atividades propostas no Projeto Araribá.

1 Em um terreno retangular, o comprimento mede o dobro da largura e o perimetro é igual a 60 metros. Determine a área, a medida do comprimento e a largura do terreno. $200 \mathrm{~m}^{2}$ (área); $20 \mathrm{~m}$ (comprimento); $10 \mathrm{~m}$ (largura)

2 Escreva no caderno uma equação que expresse cada situação abaixo. Em seguida, resolva-as.
a) Um número natural somado com sua quarta parte é igual a $25, x+\frac{x}{4}=25 ; x=20$
b) $O$ oposto de um número inteiro multiplicado por 7 é igual $a-147,7 \cdot(-x)=-147 ; x=21$
c) O triplo de um número racional somado com 8 é igual a 10. $3 x+8=10 ; x=\frac{2}{3}$

3 Copie o quadro no caderno e complete-o.

\begin{tabular}{|c|c|c|}
\hline Equação & $\begin{array}{c}\text { Conjunto } \\
\text { universo }\end{array}$ & $\begin{array}{c}\text { Solução da } \\
\text { equaçăo }\end{array}$ \\
\hline$x-3=2 x$ & $\mathbb{Q}$ & -3 \\
\hline$x+7=3$ & $\mathbb{N}$ & \\
\hline $8-x=2+x$ & $\mathbf{Z}$ & \\
\hline $17 x=-15 x$ & $\mathbb{Q}$ & \\
\hline$-x=3 x+5$ & $\mathbb{Q}$ & \\
\hline $100=4 x$ & $\mathbb{N}$ & \\
\hline
\end{tabular}

Fonte: Editora Moderna (2014, p. 141).

Figura 10 - Atividades propostas no Projeto Teláris.

24. Passe da linguagem usual para uma equação e resolva em seu caderno:

a) Qual é o número que somado com 38 tem como resultado o número 115 ? $x+38=115 ; x=77$

b) De qual número devemos subtrair 147 para obter como resultado o número 58 ?

$x-147=58 ; x=205$

c) Que fração devemos somar a $\frac{2}{3}$ para obter $\frac{17}{12} ? x+\frac{2}{3}=\frac{17}{12} ; x=\frac{3}{4}$

d) Sete vezes um número é -91 . Que número é esse? $7 x=-91 ; x=-13$

e) A metade da idade de Paulo é 19 anos. Qual é a idade de Paulo? $\frac{x}{2}=19 ; x=38$. A idade de Paulo é

25. Resolva as equações a seguir em seu caderno.
a) $t+21=6 t=-15$
c) $-5=y-8 y=3$
e) $6 x=84 x=14$
g) $-3 x=27 x=-9$
b) $9=x+17 x=-8$
d) $a-10=-13 a=-3$
f) $x: 7=77 x=539$
h) $\frac{2 y}{5}=4 y=10$

26. Faça em seu caderno a verificação das respostas das duas situaç̃es resolvidas ${ }^{10)} 3 \cdot 27=81 ; 81+10=91$;

28. Resolva os problemas abaixo em seu caderno por meio de equações:

27. Resolva em seu caderno estas equaçôes aplicando as operações inversas:
a) $y-426=700$
c) $6 x-19=71 x=15$
b) $\frac{a}{6}=132 a=792$
d) $\frac{2 x}{5}+4=10 \quad x=15$

a) Mariana comprou um livro por R\$25,00 e quatro canetas iguais, gastando R 39,00 no total. Qual fol o preço de cada caneta?RS 3,50

b) Descubra qual e o número: a diferença entre sua terça parte e 8 è igual a 19.81

Fonte: Figura elaborada a partir de Dante (2015, p. 129). 
Bianchini mostra uma maior variedade de atividades propostas. Na Figura 11, podemos identificar cinco atividades que exigem diferentes interpretações das representações abordadas. A primeira exibe uma equação na forma figural (desenho de uma balança) e solicita que se faça a conversão para o registro algébrico, seguido de um tratamento enunciado para o registro figural, que não é apresentado ao estudante, e uma nova conversão para o registro algébrico. A segunda questão exibe a representação algébrica e pede a realização de tratamentos até se determinar a solução. Na questão 31, observamos uma atividade dissertativa e na questão 32 (Figura 11) uma atividade que relembra definições estudadas no ano anterior, tais como o conjunto dos números inteiros e dos números racionais, associando os dois conteúdos. Para finalizar, na última questão podemos observar a proposta da resolução de um problema ilustrado, contendo informações na figura e no enunciado, exigindo do estudante uma interpretação não só do problema mais também da imagem. Neste caso, após estas interpretações, o estudante deveria realizar um tratamento no registro figural, de forma a denotar a altura das caixas como uma incógnita, e, possivelmente, a conversão desta nova figura para o registro algébrico na busca por solucionar o problema. Tendo a altura de cada caixa, o estudante deverá voltar ao registro figural e determinar a altura de cada pila, ou ainda, perceber que cada lado da sua equação inicial determina tal altura. Desse modo, Bianchini (2015) mantém a perspectiva de uma abordagem com o enfoque nos registros algébrico e figural, buscando a conversão e manipulação destes.

Figura 11 - Atividades propostas no livro Matemática Bianchini.

29 O esquema a seguir mostra uma balança em equilíbrio.

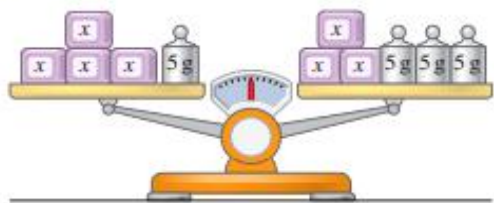

a) Determine a equação que a balança está representando. $4 x+5=3 x+15$

b) Determine a equação que a balança representa quando se retiram de cada prato 3 cubos $x$ e 1 peso de $5 \mathrm{~g}$. $x=10$

c) Qual é a massa de cada cubo? $10 \mathrm{~g}$

30 Resolva as equações aplicando as propriedades estudadas.
a) $y+9=3 \quad y=-6$
d) $3 x=-12 \quad x=-4$
b) $x-12=15 \quad x=27$
e) $3 x=10 \quad x=\frac{10}{3}$
c) $y+5=-4$
f) $5 x=90 \quad x=18$

31 Das equações da atividade anterior, se considerarmos como conjunto universo o conjunto dos números inteiros, todas as equações terão soluções?

E se considerarmos como conjunto universo o conjunto dos números naturais? Justifique suas respostas.
32 A raiz da equação

$2 x+1+5(x-3)=3(x+1)+x$ é um número: allernativa d
a) menor que -2 .
b) maior que 30 .
c) inteiro.
d) racional não inteiro.
e) negativo.

33 Com as 10 caixas que tenho, fiz duas pilhas de mesma altura, conforme mostra o desenho.
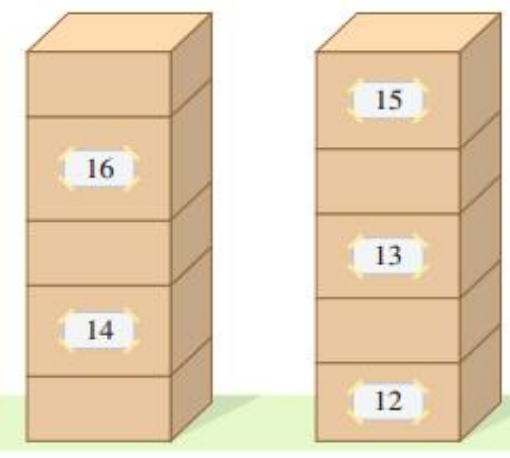

Observe que, em algumas caixas, coloquei um adesivo com um número que representa sua altura em centímetro. As que estão sem adesivo possuem a mesma altura.

a) Calcule a altura das caixas sem adesivo. $10 \mathrm{~cm}$ b) Qual é a altura de cada pilha de caixas? $60 \mathrm{~cm}$

Fonte: Bianchini (2015, p. 113). 
Desta forma, para resumir todas as situações apresentadas e descritas até este momento em cada livro, elaboramos o Quadro 1, mostrando os tipos de tratamentos e conversões observados durante a abordagem do conteúdo, dos exemplos e dos exercícios em cada um dos livros.

Quadro 1 - Possibilidades de tratamentos e conversões observados em cada um dos livros.

\begin{tabular}{|c|c|c|c|c|c|}
\hline \multirow{2}{*}{$\begin{array}{c}\text { Livro } \\
\text { analisado }\end{array}$} & \multirow{2}{*}{$\begin{array}{c}\text { Objeto } \\
\text { Matemático }\end{array}$} & \multicolumn{2}{|c|}{ Tratamentos } & \multicolumn{2}{|c|}{ Conversões } \\
\hline & & Conteúdo & Exercícios & Conteúdo & Exercícios \\
\hline $\begin{array}{l}\text { Matemática } \\
\text { Bianchini }\end{array}$ & \multirow{3}{*}{$\begin{array}{l}\text { Equações do } \\
\text { primeiro grau } \\
\text { com uma } \\
\text { incógnita }\end{array}$} & $\begin{array}{l}\text { Algébrico } \\
\text { Figural } \\
\text { Língua natural }\end{array}$ & $\begin{array}{l}\text { Algébrico } \\
\text { Figural } \\
\text { Língua natural }\end{array}$ & $\begin{array}{l}\text { Fig. } \rightarrow \text { Alg. } \\
\text { Alg. } \rightarrow \text { Fig. }\end{array}$ & $\begin{array}{l}\text { Fig. } \rightarrow \text { Alg. } \\
\text { Alg. } \rightarrow \text { Fig. }\end{array}$ \\
\hline $\begin{array}{l}\text { Projeto } \\
\text { Araribá }\end{array}$ & & $\begin{array}{c}\text { Algébrico } \\
\text { Língua Natural }\end{array}$ & Algébrico & L. Nat. $\rightarrow$ Alg. & $\begin{array}{c}\text { L. Nat. } \rightarrow \text { Alg. } \\
\text { L. Nat. } \rightarrow \text { Fig. } \\
\text { Fig. } \rightarrow \text { Alg. }\end{array}$ \\
\hline Projeto Teláris & & $\begin{array}{c}\text { Algébrico } \\
\text { Língua Natural }\end{array}$ & Algébrico & L. Nat. $\rightarrow$ Alg. & L. Nat. $\rightarrow$ Alg. \\
\hline
\end{tabular}

Fonte: Elaborado pelos autores (2020).

Ao observarmos os dados dispostos na tabela, e o que se percebe através dos livros, podemos notar que o registro mais presente nos três livros, tanto na abordagem do conteúdo quanto nos exercícios, é o registro algébrico, seguido pelo uso do registro da língua natural que em geral está também mesclada com o registro algébrico. Destacamos o livro Matemática Bianchini, que, além destes dois registros, ainda aborda desde o início do conteúdo o registro figural e nas atividades o registro discursivo. Biachini (2015) proporciona uma operação mais completa nas conversões propostas entre o registro figural e algébrico, o que pode levar a uma melhor coordenação destes registros pelo estudante. Já no Projeto Araribá o processo de conversão durante a abordagem do conteúdo só se observa quando autor apresenta a definição de EPG e exemplos desta, ademais o autor possibilita diversas conversões no decorrer das atividades propostas, algumas indicadas explicitamente nas questões. Já o Projeto Teláris de Dante (2015), assim como o projeto Araribá, dá foco aos processos de conversão em questões inteiramente em língua natural para o registro algébrico, o que deve auxiliar no processo de relação do conteúdo novo com os conhecimentos já adquiridos pelos estudantes. Contudo, a opção por focar em um processo de conversão em um único sentido pode fazer com que o processo de aprendizagem dos estudantes não seja potencializado, segundo a TRRS.

Como dito anteriormente, nossa análise teve como foco a seção de EPG dos livros didáticos, contudo é importante destacar que certos elementos que não apareceram nas análises podem ser observados em seções anteriores ou posteriores. Por exemplo, ao abordar o conteúdo de expressões algébricas, Bianchini (2015) apresenta o uso das conversões da língua natural para o registro algébrico, algo que não pode ser observado na discussão de EPG. Quanto ao tema de equação e raiz da equação, o autor já utiliza o uso das conversões da registro figural da balança com a expressão algébrica. Já o Projeto Araribá (2014), ao abordar expressões 
algébricas faz o uso das conversões da língua natural, bem como do registro figural com o uso de polígonos planos, para o registro algébrico. De forma parecida a utilizada por Bianchini (2015), a obra apresenta o uso da balança e da conversão para a expressão algébrica, logo antes de abordar o conteúdo de EPG. Na parte anterior ao tópico de EPG, o Projeto Teláris (2015) discute também a ideia de usar letras para determinar valores desconhecidos, equação, incógnita e solução, com o uso de registros de maneira semelhante ao observado. A relação da equação com o equilíbrio da balança só é abordada na sequência do conteúdo de EPG, sob uma perspectiva semelhante à observada nas outras obras. Desta forma, os livros apresentam semelhanças quanto aos tratamentos e conversões utilizados quando se observa além da seção de EPG, mas a opção por uma exposição do conteúdo com menos processos vai na contramão das perspectivas de aprendizagem da Teoria de Registros de Representação Semiótica, de forma que tal escolha possa afetar negativamente o processo aprendizagem do estudante.

\section{Considerações finais}

O presente artigo teve como foco uma análise do conteúdo de EPG com uma incógnita em três livros didáticos de Matemática do sétimo ano do Ensino Fundamental, listados pela PNLD 2017. A pesquisa tomou como base a TRRS, visando principalmente os registros utilizados no material didático, com enfoque nos tratamentos e conversões, sendo o último relacionado diretamente com o processo cognitivo de aprendizagem matemática.

Por meio da pesquisa realizada foi possível perceber que os livros didáticos usam diversos registros no decorrer do conteúdo, mas uma abordagem mais produtiva poderia suprir a necessidade de reconhecer um mesmo objeto matemático em diversos registros, bem como conseguir coordenar e transitar entre diferentes representações. A escolha por uma abordagem com poucos registros e conversões entre registros, bem como conversões em um único sentido, faz com que se justifique, com base na TRRS, a dificuldade que, por vezes, é observada em alguns estudantes. Embora o livro Matemática Bianchini tenha apresentado uma quantidade razoável de registros, realizando tratamentos e conversões, o autor possibilita a conversão, em ambos sentidos, apenas com os registros figural e algébrico. Ainda, observamos durante a apresentação do conteúdo que os outros livros de detêm apenas a conversão do registro em língua natural para o algébrico, o qual, segundo Duval, não torna o processo compreensão matemática mais eficaz. No entanto, é importante relembrar que nos ativemos apenas a uma parte dos livros, não podendo então afirmar que tais processos não ocorram em nenhum momento das obras.

A partir desta análise, é possível ressaltar a importância de o professor ser crítico em relação ao livro didático. Este recurso deve ser usado como ferramenta de ensino, com uma utilização adequada, buscando complementar o que este material oferece. Podemos perceber que os livros ainda não contemplam todas as concepções para a aprendizagem dos estudantes, segundo a perspectiva de Duval, uma vez que é preciso proporcionar uma riqueza de 
representações de um mesmo objeto matemático, possibilitando ao estudante a coordenação destes.

Este trabalho, assim como outros, abre caminho para investigações sobre a maneira como os livros didáticos atuais abordam os objetos matemáticos, à luz da TRRS. Uma primeira pergunta que poderia ser feita é se estas coleções, ou outras, apresentam uma abordagem que vai ao encontro do que afirma a TRRS quanto ao ensino de equações, não apenas das EPG ou, ao menos, tratando das EPG com uma incógnita de forma mais ampla, se debruçando sobre o livro de forma integral. Do modo semelhante, caberia verificar como se dá o uso do livro didático em sala de aula pelo professor, de maneira a compreender a relação deste profissional com o material usado.

\section{Referências}

BIANCHINI, E. Matemática Bianchini. São Paulo: Moderna, 2015.

BRASIL. Parâmetros Curriculares Nacionais. Brasília, DF: MEC/SEF, 1998.

CAMARGO, A. P. S. Aprendizagem em Álgebra, uma Investigação no Oitavo Ano. 2014. 51f. Monografia (Licenciatura em Matemática) - Departamento de Matemática e Estatística, Universidade Federal de Rondônia, Paraná, 2014.

DANTE, L. R. Projeto Teláris: Matemática 7. São Paulo: Ática, 2015.

DUVAL, R. Registros de Representações Semióticas e Funcionamento Cognitivo da Compreensão em Matemática. In: MACHADO, S. D. A. (Org.). Aprendizagem em Matemática: registros de representação semiótica. Campinas, SP: Papirus, p. 11-33, 2003.

DUVAL, R. Semiósis e pensamento humano: Registros semióticos e aprendizagens intelectuais. Trad.: LEVY, L. F.; SILVEIRA, M. R. A. da. São Paulo: Livraria da Física, 2009.

EDITORA MODERNA. Projeto Araribá: Matemática 7. São Paulo: Moderna, 2014.

FONSECA, J. J. S. Metodologia da pesquisa científica. Fortaleza: UEC, 2002.

GIL, A. C. Como elaborar projetos de pesquisa. 4 ed. São Paulo: Atlas, 2007.

GUIMARÃES, G.; GITIRANA, V.; CAVALCANTI, M.; MARQUES, M. Análise das atividades sobre representações gráficas nos livros didáticos de matemática. SIMPÓSIO INTERNACIONAL DE EDUCAÇÃO MATEMÁTICA, 2., Recife, 2008. Anais... Universidade Federal Rural de Pernambuco, 2008.

MENEZES, D. L. Abecedário da Álgebra. São Paulo: Nobel, 1970.

MORETTI, M. T. O papel dos registros de representação na aprendizagem de Matemática. Revista Contrapontos, Itajaí, SC, ano 2, n. 3, p. 423-437, set./dez. 2002. Disponível em: https://siaiap32.univali.br/seer/index.php/rc/article/view/180. Acesso em: 19 abr. 2020.

OLIVEIRA, A. T. C. C. Reflexões sobre a aprendizagem da álgebra. Educação Matemática em Revista, Brasília, n. 12, ano 9, p. 35-39, jun. 2002. Disponível em: 
http://sbem.iuri0094.hospedagemdesites.ws/revista/index.php/emr/article/view/1100. Acesso em: 19 abr. 2020.

PONTE, J. P. da. As equações nos manuais escolares. Revista Brasileira de História da Matemática, v. 4, n. 8, p. 149-170, 2003. Disponível em:

http://www.rbhm.org.br/issues/RBHM\%20-\%20vol.4,\%20no8,\%20outubro\%20(2004)/4\%20\%20Ponte.pdf. Acesso em: 19 abr. 2020.

RODRIGUÊS, J. S.; COSTA, D. A. da. A Comissão dos Quinze e os Primeiros Movimentos Acerca do Ensino da Álgebra na Escola Primária Brasileira. Acta Scientiae, Canoas, v. 21, n. 6, p. 150172, nov./dez. 2019. DOI: https://doi.org/10.17648/acta.scientiae.5450.

SANTAELLA, L. O que é semiótica. São Paulo: Brasiliense, 2002.

USISKIN, Z. Concepções sobre a álgebra da escola média e utilizações das variáveis. In: COXFORD, A. F.; SHULTE, A. P. As idéias da álgebra. São Paulo: Atual, p. 9-21, 1995. 